\title{
Risk of cervical cancer associated with mild dyskaryosis
}

\author{
J H Robertson, Bertha E Woodend, E H Crozier, June Hutchinson
}

\begin{abstract}
In a survey of 1781 patients who had mild dyskaryosis in a cervical smear taken between 1965 and 1984 invasive cancer occurred in 10 women. In four cancer was diagnosed soon after presentation, and in three it developed some years after default from follow up. Invasion occurred in one patient during cytological surveillance and in a further two after referral for colposcopic supervision. A poor correlation was found between a single cervical smear showing mild dyskaryosis and biopsy results. This was, however, improved by a series of smears. During initial surveillance cervical smear results reverted to normal in $46 \%$ of our patients within two years. During longer term follow up none of these patients developed invasive cancer, and life table analysis showed that three quarters had not relapsed after 14 years. We also found no evidence to suggest that preinvasive disease is more rapidly progressive in younger women.
\end{abstract}

Our results indicate that cytological surveillance is acceptably safe provided that biopsy is advised if dyskaryosis persists.

\section{Introduction}

Formerly a cervical smear that showed mild dyskaryosis in keeping with a mild epithelial dysplasia (cervical intraepithelial neoplasia I) was considered to be only remotely related to invasive cancer. It was believed that these lesions often regressed spontaneously and that for those that persisted there was generally a long latent period before invasive disease supervened. It was therefore common practice to keep patients who had this abnormality under cytological surveillance by periodically repeating smears and to refer them to a gynaecologist only if the abnormality persisted over 12 to 18 months. ${ }^{1}$

Recently, however, the management of these patients has become controversial. With the wider use of colposcopy reports have described a lack of correlation between the findings of cytology and biopsy, severe preinvasive disease often being present when the cervical smear showed only mild dyskaryosis. Furthermore, both lesions of cervical intraepithelial neoplasia and invasive cervical cancer have become more common in younger women, and it has been suggested that preinvasive disease may now progress more rapidly to cancer, especially in younger women Consequently, doctors are now advised that mildly dyskaryotic cells in a smear should be treated with the utmost seriousness, that the practice of cytological surveillance is unwise, and that all patients who have mildly dyskaryotic cells should be referred for colposcopy. ${ }^{23}$

Such advice presents difficulties, as smears that show mild dyskaryosis far outnumber those that show a more severe abnormality, which are already causing colposcopy clinics to be overloaded. Before embarking on the large scale expansion of colposcopy facilities it is important to obtain firm evidence that relying on cervical cytology for keeping these patients under surveillance is now unsafe.

We therefore studied the outcome for 1781 patients who were found to have a mildly dyskaryotic smear between 1965 and 1984. During this time the advice in our laboratory had been to keep such patients under cytological review to allow the severity of the lesion to be further assessed. The object of the present study was to determine the risk of invasive cancer with this method of surveillance, the correlation between the cytology results and the biopsy results, and the incidence of spontaneous regression of these cytologically mild lesions. We also attempted to discover whether preinvasive lesions have become more aggressive since 1977 or progress more rapidly in younger women.

\section{Patients and methods}

This hospital provided a regional community cytology service for Northern Ireland from 1965 to 1986, during which time the cytology records were kept by computer, and the laboratory operated a recall system for those patients whose smear results were abnormal. The patients' records were also kept updated with biopsy results and clinical information. We studied the records of 1781 women who had mildly dyskaryotic smears from 1965 to 1984 and were followed up until mid-1987. In addition, we surveyed the records of all the histopathology departments in the province to identify all women whose biopsy results showed that they had invasive cervical cancer between 1965 and June 1987. These names were matched with our cytology records on the computer to ensure their completeness and also to determine the incidence of invasive disease in those patients who had been lost to follow up. In describing the histological severity of preinvasive lesions we have used only two categories in this study-namely, cervical intraepithelial neoplasia I or II and cervical intraepithelial neoplasia III-as it was often difficult to define the milder lesions more precisely from the histological reports.

We first studied the experience of 1781 women during the two years after their initial smear, this being the period during which the laboratory advised cytological surveillance. Our practice was to request a further smear, and if this showed similar changes repeat smears were asked for every six months. During these first two years these patients would therefore have had a total of five smears. Biopsy was advised during this time if the smear showed evidence of a more severe dyskaryosis or if the patient had abnormal bleeding or a clinically suspect cervix. Evidence of mild dyskaryosis persisting for 18 to 24 months also prompted laboratory advice to take a biopsy sample.

The dysplasia was considered to have regressed if the patient had two consecutive normal smear results. These patients continued to be followed up, having recalls every six months during the first 18 months and thereafter every year.

\section{Results}

\section{OUTCOME DURING FIRST TWO YEARS}

Not all of the patients followed the regimen recommended by the laboratory, and we found that the further course of these 1781 women followed one of five patterns (table I). In 315 patients biopsy was performed on the request of the clinician after only the first or second mildly dyskaryotic smear. One patient had an invasive carcinoma, and cervical intraepithelial neoplasia III was found in 38 . The patient who had invasive disease had only one smear, as the clinical findings indicated immediate biopsy.

Mild dyskaryosis persisted in the cervical smear for
Correspondence to: Dr Robertson. 


\begin{tabular}{|c|c|c|c|c|c|c|c|}
\hline \multirow[b]{2}{*}{ Smear results } & \multirow{2}{*}{$\begin{array}{c}\text { No } \\
\text { of } \\
\text { patients }\end{array}$} & \multicolumn{6}{|c|}{ Biopsy results } \\
\hline & & Normal & Condyloma & $\begin{array}{l}\text { CIN I or } \\
\text { CIN II }\end{array}$ & CIN III & $\begin{array}{c}\text { Invasive } \\
\text { carcinoma }\end{array}$ & $\begin{array}{c}\text { Not } \\
\text { known }\end{array}$ \\
\hline Mild dyskaryosis in one or two smears with biopsy & 315 & 101 & 2 & 173 & 381. & 1 & 0 \\
\hline Persisting mild dyskaryosis with biopsy at $18-24$ months & 145 & 19 & 2 & 67 & $39\}^{77}$ & 0 & 18 \\
\hline More severe dyskaryosis in second or later smear with biopsy & 262 & 20 & 0 & 115 & 124 & 3 & 0 \\
\hline Smear regressed to normal & 625 & - & - & - & - & - & - \\
\hline Total & 1347 & 140 & 4 & 355 & 201 & 4 & 18 \\
\hline Lost to follow up & 434 & & & & & & \\
\hline
\end{tabular}

$\mathrm{CIN}=$ Cervical intraepithelial neoplasia

18-24 months in 145 women, and biopsy was advised. Of the results that are known, 39 were found to have cervical intraepithelial neoplasia III. There were no invasive lesions.

In 262 women biopsy was advised by the laboratory because of a later smear showing more severe dyskaryosis. In the three invasive cancers found and in three quarters of the 124 cervical intraepithelial neoplasia III lesions the more severe nature of the epithelial abnormality became evident on the second cervial smear, indicating that the lesion had not increased in severity but instead had been underestimated by the initial smear.

Spontaneous regression of the dysplasia, as assessed from two consecutive negative smear results, occurred in 625 patients. A further 434 patients were lost to follow up, as they defaulted before the importance of their abnormal smear could be assessed.

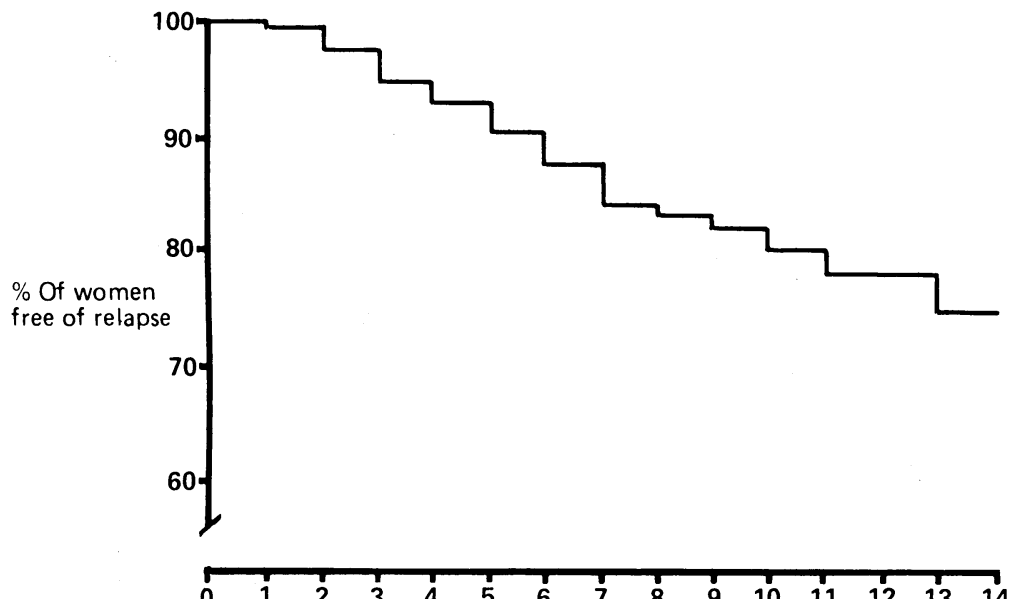

No of women

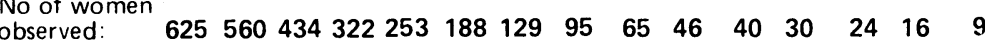
FIG 1-Life table of subsequent incidence of relapse for all patients (1965-84) whose smears initially regressed

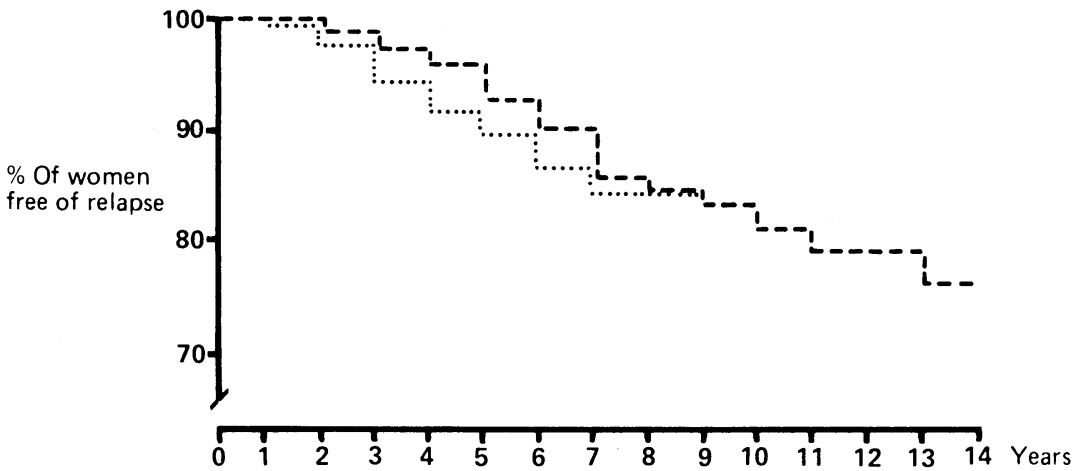

No of women

observed:

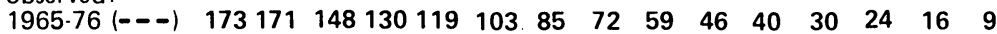

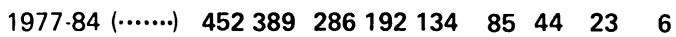

FIG 2-Life table of subsequent incidence of relapse for patients related to time of initial smear
Thus of the 1347 patients who could be followed up during these two years, biopsy results showed invasive cancer in four patients. In 201 patients (15\%) cervical intraepithelial neoplasia III was found. In only 77 instances, however, was the severity of the lesion not predicted by cytology, and in half of these only one or two smears had been taken, the others showing a pattern of persisting mild dyskaryosis throughout the period of surveillance (table I). In a further 625 patients, who made up $46 \%$ of those followed up, the lesion regressed without biopsy or treatment.

\section{FOLLOW UP AFTER REGRESSION}

Figure 1 shows in life table form the results of follow up of the 625 patients who regressed cytologically. ${ }^{4}$ It shows that after the first year there was a pattern of continuing relapse extending over 14 years as indicated by a further abnormal smear. Despite this, three quarters of these women would be expected to be free of relapse at 14 years. Of the 54 patients who relapsed, 35 are known to have required a biopsy, a cervical intraepithelial neoplasia III lesion being found in 15 cases. A single patient was found to have an invasive carcinoma one year after apparent regression of her previous mildly dyskaryotic smear.

To determine whether there was evidence that women who had mildly dyskaryotic smears had become more susceptible to relapse in recent years life tables were drawn showing the incidence of relapse of those whose first smear was taken from 1965 to 1976 (173 patients) and compared with those whose first smear was taken from 1977 to 1984 (452 patients). Figure 2 shows the incidence of relapse of these two groups; there was no significant difference between them $\left(\chi^{2}=0.71, \mathrm{df}=1, \mathrm{p}=0.40\right)$. We chose to compare these two periods, as it was from 1977 that our incidence of positive smear results, especially in women aged under 45, considerably increased (fig 3). We also assessed the effect of age by comparing the incidence of relapse in women older than 35 at the time of their first smear with that in younger women (fig 4). Again, there was no significant difference in the incidence of relapse $\left(\chi^{2}=0.03, \mathrm{df}=1, \mathrm{p}=0.86\right)$.

\section{INVASIVE CANCERS}

From our survey of invasive cancers in Northern Ireland we found 10 cases of squamous carcinoma among the 1781 patients who had mild dyskaryosis. Table II summarises their cervical smear results and clinical history. Three patients clearly had invasive disease from the outset (cases 1, 4, and 5). One of these had a clinically evident carcinoma on presentation and had only one smear, while in the other two the second smear indicated the need for biopsy. In another two patients (cases 3 and 6) diagnosis was delayed because of pregnancy. It was not until the postnatal period that their second smears, which showed more severe changes, were taken. In case 6 colposcopic biopsy showed cervical intraepithelial neoplasia III, and two further severely dyskaryotic smears from the clinic preceded the diagnosis of carcinoma 10 months later. 


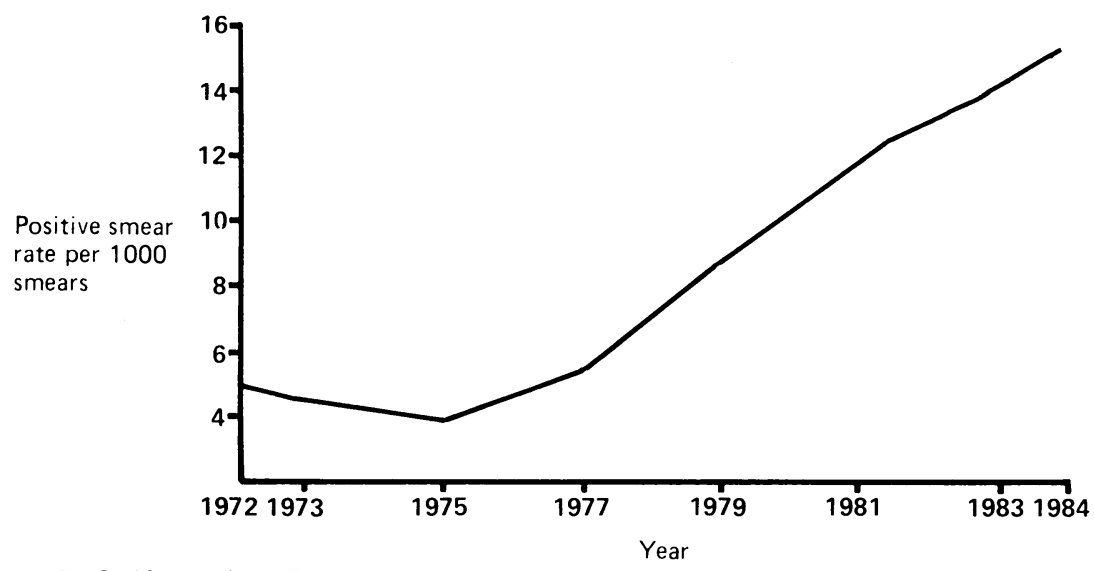

FIG 3-Incidence of positive smear results in women aged under 45 years between 1972 and 1984

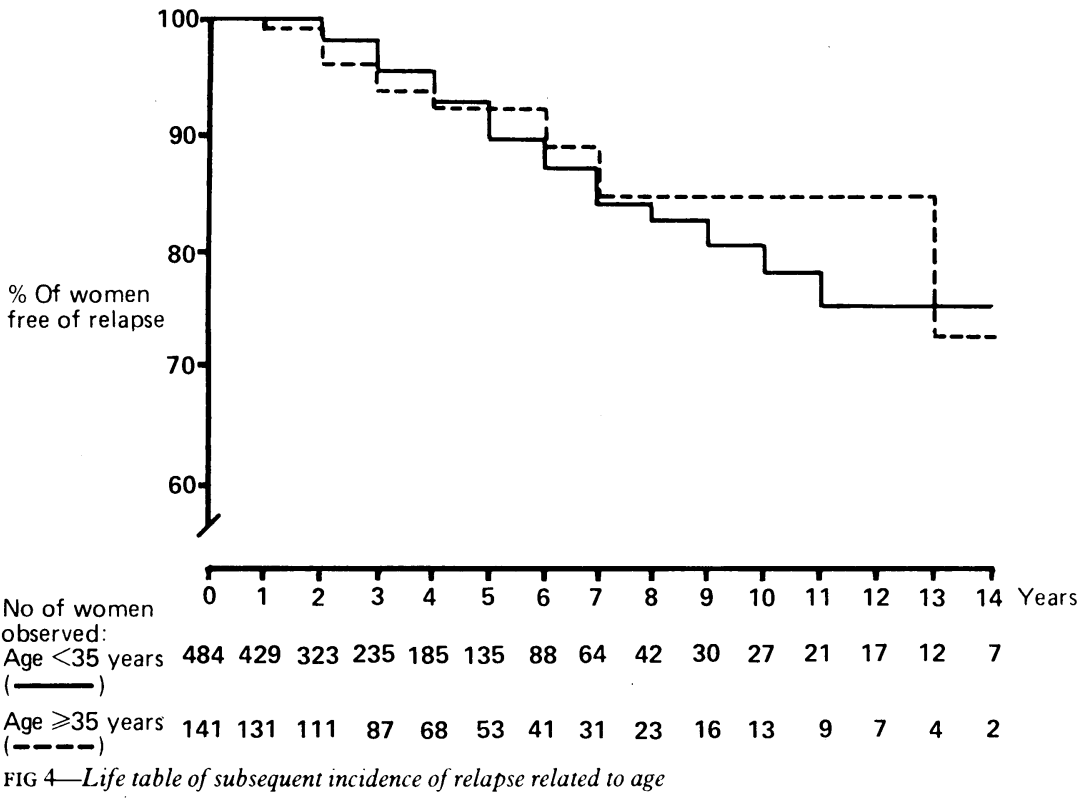

A further patient (case 2) was also referred for colposcopy, as her smears had shown persisting mild dyskaryosis for two years. Biopsy showed cervical intraepithelial neoplasia I, and despite further review carcinoma was found four years later. In case 7 the patient had two consecutive normal smears but a year later presented with invasive disease, two years after her first smear. The remaining three carcinomas (cases 8,9 , and 10 ) occurred among the 434 patients who were lost to follow up. All three patients had had only one mildly dyskaryotic smear and were found to have invasive cancer two, six, and 12 years later.

\section{Discussion}

Conclusions based on our results must take account of the drawbacks inherent in any retrospective study. The patients were not all managed in a uniform manner, and the duration of follow up was determined by the patients' willingness to attend for review. Furthermore, it is difficult to assess the severity of preinvasive neoplastic changes in the cervix, as appreciable variation can occur in interpreting results not only of cervical smears but also of surgical biopsies. The influence of these last two variables has been reduced, as all the smears in this study were reported by one cytopathologist (JHR), and the biopsy results have been reduced to two categories-namely, cervical intraepithelial neoplasia I or II and cervical intraepithelial neoplasia III.

On the other hand the main purpose of this study was to determine whether our practice of cytological surveillance of women who have mildly dyskaryotic smears was safe or resulted in an unacceptable risk of delayed diagnosis of invasive cancer. We were able to do this, as our record of all cases of invasive disease is quite complete, being based not only on our regional cytology computer records but also on a survey of the records of all the histopathology departments in the province. Among the 1347 patients who could be followed up seven cases of carcinoma were found. It is well recognised that cervical cytology can give misleading results with invasive cancer, the technique being most suitable for diagnosing cervical intraepithelial neoplasia. Three patients had invasive disease from the outset but showed only mild dyskaryosis in their initial smear. In two of these, however, the second smear indicated the need for biopsy, and in the third the disease was clinically evident. In two other patients the second smear also showed severe dyskaryosis, but pregnancy was a factor in causing a delay in diagnosis. In one patient our method of cytological surveillance failed, as carcinoma developed after the dysplasia had apparently regressed. On the other hand, in this series colposcopic surveillance fared no better, as two patients developed a carcinoma 10 months and four years after referral.

It is clear from this series that mild dyskaryosis in a single cervical smear can underestimate the severity of the epithelial abnormality in the cervix. Of the 1347 patients who could be followed up, $26 \%$ showed evidence from cytology or biopsy of a more severe lesion during the first two years of observation. In some patients this might have resulted from progression of cervical intraepithelial neoplasia I. We found, however, that in most it was clear that the result of the initial smear underestimated the severity of the lesion. Thus although the first smear lacked diagnostic precision, this improved with subsequent smears. In our series the period of initial cytological surveillance was found to be safe provided that the patient underwent biopsy if the smear pattern worsened or mild dyskaryosis persisted. With these referral criteria, only in one case of invasive carcinoma can cytological surveillance be said to have failed (if the delayed diagnosis because of pregnancy is discounted).

In 625 of 1347 patients $(46 \%)$ the smear results returned to normal within two years without the women undergoing biopsy. The follow up curve shows that three quarters of these should be free from relapse

TABLE II-Cytological and clinical history of patients who developed invasive cancer

\begin{tabular}{|c|c|c|c|c|}
\hline Case No & Smear history & Age (years) & Clinical features & $\begin{array}{l}\text { Time from initial smear to } \\
\text { carcinoma being diagnosed }\end{array}$ \\
\hline 1 & Mild dyskaryosis in one smear & 67 & Clinically evident & \\
\hline 2 & \multirow{2}{*}{ Persisting mild dyskaryosis } & 37 & Colposcopy 2 years after initial smear & 6 years \\
\hline 31 & & 31 & Pregnant at time of initial smear & 8 months \\
\hline 4 & \multirow{3}{*}{ More severe dyskaryosis in second smear } & 38 & & 2 months \\
\hline 5 & & 54 & & 1 month \\
\hline 6) & & 29 & Pregnant at time of initial smear; colposcopy 11 months after initial smear & 21 months \\
\hline 7 & \multirow[t]{2}{*}{ Smear regressed to normal } & 51 & & 2 years \\
\hline 8 & & 47 & Diathermy to cervix after initial smear & 2 years \\
\hline 9\} & Lost to follow up & 24 & & 6 years \\
\hline 10) & & 42 & & 12 years \\
\hline
\end{tabular}


at 14 years. We found no difference between the incidence of relapse in younger women compared with that in older women or between those who had their first smears taken before and after 1977. These findings do not support a previous suggestion that preinvasive disease is especially likely to be more aggressive in younger women.

It is interesting that the relapses occurred continually throughout the whole of the follow up period. Some of these relapses probably reflect persistence of the initial cervical intraepithelial neoplasia despite previous negative smears, but this seems unlikely for those occurring in later years in women who have had many previously negative smears, and reinfection with the papillomavirus has been found to be common." Again, persistence of the initial lesion would be expected to give an excess of relapses in the early years, which was not found in our study. This pattern of continuing relapse contrasts with the few relapses we found after surgical treatment of cervical intraepithelial neoplasia III. This supports a similar observation by Richart et al, who suggested that cryotherapy may stimulate an immune reaction to prevent reinfection with the papillomavirus. ${ }^{x}$

At present, some doctors recommend that mildly dyskaryotic smears should be treated with the utmost seriousness and that all women who have smears that contain dyskaryotic cells should be referred for colposcopy, surveillance by cytology being inadequate. Our results suggest that the strongest case for immediate colposcopy is to detect those women who present with mild dyskaryosis but who have an invasive carcinoma, as it is in these circumstances that cytology is probably least effective. One problem is that cancer can result not only in a misleading mild dyskaryosis but also in blood stained smears or smears containing "borderline" cells or considerable inflammatory changes. The number of such smears is legion. We have also been impressed by the experience required for accurate colposcopy, and indeed in our series more diagnostic errors resulted from colposcopy than from cytology. These would be multiplied if colposcopy were adopted virtually as a screening procedure. Our results also raise the question of cost effectiveness. In the 1347 patients followed up there occurred only seven carcinomas. Frequent needless examinations would also be carried out, as mild dyskaryosis in many patients spontaneously regresses. Furthermore, we could find no evidence to suggest that a more rapidly progressive form of preinvasive disease that would indicate urgent colposcopy is present in younger women.

In agreement with Brown and Phillips our findings show that cytological review is quite safe provided that all patients who show a persisting smear abnormality are referred for colposcopy and biopsy. ${ }^{9}$ In view of the number of cervical intraepithelial neoplasia III lesions that we found to be associated with persisting mild dyskaryosis, however, we would now prefer to shorten the initial review period before biopsy to 12 to 18 months. Pregnancy also presents difficulties for cytological diagnosis. A further factor that may affect treatment policy is our confirmation that biopsy or laser treatment seems to confer protection against later infection by papillomavirus.

We thank Dr C Patterson, department of medical statistics, Queen's University, Belfast, for help with statistical analysis, the histopathologists of Northern Ireland for access to their records, and the medical photography department, Belfast City Hospital for the illustrations. We are also grateful to Mrs $\mathrm{J}$ Hamill and Miss F Ferris for secretarial help.

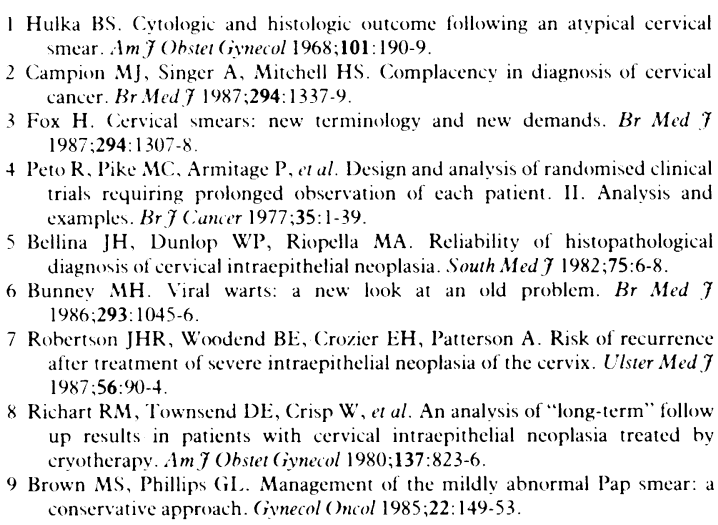
smear. Am fobstel (jinecol 1968;101:190-9.

2 Campion .MJ, Singer A, Mitchell HS. Complacency in diagnosis of cervical cancer. Br.Med 7 1987:294:1337-9.

3 Fox H. Cervical smears: new terminology and new demands. Br Med 7 $1987 ; 294: 1307-8$

+ Peto R. Pike MC. Armitage P, et al. Design and analysis of randomised clinical trials requiring prolonged observation of each patient. II. Analysis and examples. Br f Cancer 1977;35:1-39.

5 Bellina JH, Dunlop WP, Riopella MA. Reliability of histopathological diagnosis of cervical intraepithelial neoplasia. South Med $\mathcal{f}$ 1982;75:6-8.

6 Bunney $\mathbf{M H}$. Viral warts: a new look at an old problem. Br Med 7 1986:293:1045-6.

7 Rohertson JHR, W'odend BE, Crozier EH, Patterson A. Risk of recurrence after treatment of severe intraepithelial neoplasia of the cervix. Ulster Med 7 after treatment

8 Richart RM, Townsend DE, Crisp W', et al. An analysis of "long-term" follow up results in patients with cervical intraepithelial neoplasia treated by cryotherapy. Am F Obstet (iynecol 1980;137:823-6.

9 Brown MS, Phillips (iL. Management of the mildly abnormal Pap smear: conservative approach. (ivnecol ()ncol 1985;22:149-53.

Acepted 9 March 1988

\title{
Rheumatic symptoms after cardiac surgery: a prospective study
}

\author{
Krystyna Walton, P J L Holt
}

Rheumatism Research

Centre, Manchester Royal

Infirmary, Manchester M139WL

Krystyna Walton, MRCP, senior registrar in

rheumatology and

rehabilitation

P J L Holt, $\mathrm{FRCP}$, reader in

rheumatology

Correspondence to: Dr K

Walton, Withington

Hospital, Manchester

M20 8LR.
Abstract

The incidence of different types of shoulder pain after open heart surgery was studied prospectively. Of 101 patients studied, 45 developed rheumatic symptoms during the first six weeks after the operation. Thirty eight patients reported pain in the region of the shoulder girdle with no loss of shoulder function (postpericardiotomy rheumatism). Three of these patients also had features compatible with the postpericardiotomy syndrome (fever, malaise, or pleuritic chest pain), and seven developed the syndrome without pain in the shoulder girdle. Of these 10 patients, one had generalised myalgia. Postpericardiotomy rheumatism alone was not associated with increased inflammation (measured by the erythrocyte sedimentation rate and concentration of $C$ reactive protein); immunological tests including measurement of antibodies to cardiac muscle yielded inconclusive results. Replies to a postal questionnaire showed that symptoms of postpericardiotomy rheumatism were present for over three months in $\mathbf{1 8}$ patients and for six months or longer in 14.

In view of the large number of patients now having open heart surgery postpericardiotomy rheumatism should be considered when patients report pain around the shoulders so that it is not misdiagnosed as angina.

\section{Introduction}

It has been known for 50 years that recovery from myocardial infarction may be complicated by shoulder pain of non-cardiac origin not associated with loss of shoulder function, which may start several months after the acute episode. ${ }^{2}$ This seems to be a separate entity to frozen shoulder or the shoulder-hand syndrome, in which shoulder movements are greatly restricted and the prognosis worse. ${ }^{3+}$ Arthritis or arthralgia has been described as a feature of the 